\title{
Performance, persistence and benchmarks of selected South African unit trusts for the period 1998-2002
}

\author{
G. Oldham and J.-A. Kroeger \\ Faculty of Management Studies, School of Economics and Finance, \\ University of KwaZulu-Natal, Private Bag X01, Scottsville 3209, \\ Republic of South Africa \\ oldham@ukzn.ac.za
}

Received January 2005

\begin{abstract}
Fund managers in the South African unit trust industry have an objective of generating strong alpha returns, meaning average annual returns above the respective benchmark. This paper analyses the performance of twenty South African unit trusts, selected from various sectors over the $1998-2002$ period. In all cases the benchmark used by the funds is the Johannesburg Stock Exchange All Share Index. The well-known Capital Asset Pricing Model and a three-factor Arbitrage Pricing Theory model are used in the analysis. The result shows that only four funds of the twenty analysed were able to generate a superior performance in one or more years of the five-year period. Individual unit trusts were unable to perform consistently for any length of time. The failure of the funds to meet their objective is further analysed in terms of the appropriateness of the JSE All Share Index as the benchmark. In some cases the index was not an appropriate benchmark to measure persistence in performance and sector indices were preferable. In a cross-sectional portfolio analysis there was evidence of overall persistence in performance but this was of short duration, related more to negative than positive persistence in performance. Overall, the results of the analysis do not produce convincing evidence that unit trust fund managers were able to generate consistent above average returns to their investors. Furthermore, it may be preferable from an investor's viewpoint if fund managers were to target an absolute rather than a relative benchmark.
\end{abstract}

*To whom all correspondence should be addressed.

\section{Introduction}

Investors expect superior returns from actively managed unit trusts to justify management fees and expenses incurred. This paper attempts to ascertain whether there have been funds that outperformed their benchmark and if fund managers have been able to achieve persistent superior returns for their investors. If the fund managers have not been able to meet these expectations the incentive for investing in such funds is considerably weakened. Consideration is given to the suitability of the benchmark adopted by fund managers to measure the performance of their funds. If an inappropriate target is set extraneous economic events may cause managerial performance to be misjudged. Throughout the paper performance is attributed to 'fund managers' but no attempt is made to find out to what extent the management team has changed during the period under consideration.

Positive superior returns may be defined as returns over and above the expected returns predicted by the Capital Asset Pricing Model (CAPM), as measured by Jensen's alpha. Alternatively, the Arbitrage Pricing Theory (APT) model may be used to generate expected returns. The purpose of this paper is to identify, on an annual basis, which funds out of a set of selected unit trusts offered superior returns over a five-year period. The paper then examines the persistence of superior performance to see which, if any, unit trusts were able to maintain outstanding returns over the five years. All the funds selected have adopted as a benchmark the annual return of the Johannesburg Stock Exchange (JSE) All Share Index.

The number of funds selected is rather small and the period over which performance is tested quite short but, relative to the current availability of funds, the market was limited in size prior to 1998.This paper examines the performance of twenty domestic unit trusts, selected from various sectors, for the $1998-2002$ periods. Using weekly returns, CAPM and APT tests are made for superior performance for each unit trust. For CAPM the benchmark used is the JSE All Share Index while the APT uses the Mining Resource, Financial and Industrial indices as benchmarks. A comparison is made between the two models to establish whether the additional explanatory power of the APT provides a better model in evaluating superior performance.

The Jensen measure, which tests an individual fund's performance using the alpha of CAPM, allows the performance to be classified as either superior, no different from the market, or inferior. The funds that had a superior or inferior performance in at least one year are identified. A similar exercise, but using sector indices, is carried out using the APT model. A comparison of the results permits an assessment of the appropriateness of the JSE All Share Index (ASI) as a benchmark. The use of the JSE ASI as a 
benchmark implies that the fund manager can 'beat the market' by beating the benchmark. However, fund managers cannot beat the market by mimicking the market. Superior performance must come from timing and portfolio selection. A fund that significantly outperforms the ASI will be reflected in the CAPM by a beta significantly different from unity and a positive alpha. The positive alpha is attributed to above average management skills and the beta value to specialised share selection, resulting in relatively low or high systematic risk. The unit trust's performance is not closely correlated with overall market returns but depends, instead, on concentration in certain strongly performing sectors. If the superior performance is related to concentration of the portfolio in the industrial, financial or mining sectors, the APT model should identify these sectors.

A general test for persistence of performance is carried out using the full sample of twenty Jensen alphas in each year. In a cross-sectional regression analysis the predictive ability of the previous year's alpha values on the following year's alpha values is determined for both the CAPM and the APT models. If there is any predictive ability, then the returns in one year will depend on the returns from the previous year showing that, in general, persistence in performance exists for the twenty funds.

All the funds examined chose the JSE ASI as a benchmark. It therefore seems meaningful to consider whether the ASI is an appropriate benchmark or if another benchmark would be more appropriate in identifying the success, or otherwise, of the funds selected. By selecting the ASI as the benchmark, managers are saying that they can 'beat the market'. But how appropriate is this benchmark if the fund managers focus on certain sectors such as mining, financial or industrial? The ASI is appropriate to broad diversification across all sectors. Selecting the ASI as a benchmark, when the fund manager is focusing on investments in identified sectors, may incorrectly attribute superior or inferior performance to management skills. The cause is relatively high or low sector returns and not exceptional timing or selection skills.

\section{Literature review}

\section{Introduction}

Numerous studies have been conducted, both internationally and locally, with respect to the performance and persistence in performance of mutual funds and unit trusts. Persistence of performance is important because many investors compare and select unit trusts by looking at the past performances of funds. Meyer (1998:100) states that although it is useful and quite common to judge a unit trust using past performance as a measure, many academics do not agree on this method. This is in accordance with the Efficient Market Hypothesis (EMH), which implies that past performance is no guide to future performance after adjusting for risk and other pricing factors.

\section{International studies}

Jensen (1968) studied the performance of mutual funds finding that past performance could not be used to predict future performance. The funds studied were not, on average, able to outperform the market. Furthermore, there was little evidence to show that any individual mutual fund was able to perform better than the market apart from what might be expected from pure chance. The following three studies find contrary evidence compared to Jensen's findings.

Grinblatt and Titman (1992) observed evidence of positive persistence in performance as well as noting that past performance proved to be useful to investors who were considering investing in mutual funds. The data was subject to survivorship bias but it was argued that this had a negligible influence on the results. Hendricks, Patel and Zeckhauser (1993) found statistically significant short-run persistence of performance relative to a number of benchmarks. They identified the 'hot hands' phenomenon, which represented short-run superior performance. Investors stood to gain from investing in the previous years' winners. Hot hands were not a result of survivorship bias. They did, however, also find the counterpart of the 'hot hands' phenomenon - 'icy hands' representing short run inferior performance. There were more sustained poor performers than good performers. Goetzmann and Ibbotson (1994) found persistence in performance in mutual fund returns and that past returns were a useful guide to an investor for predicting the funds' future returns. They also established a measure for the magnitude of persistence in performance.

Malkiel (1995) stated that the results from the studies carried out by Grinblatt and Titman (1992), Hendricks et al. (1993) and Goetzmann and Ibbotson (1994) could be explained by survivorship bias. Thus, Malkiel's study adjusted for survivorship bias and, after taking transaction costs into account, found that there was not any evidence of persistence in performance. Elton, Gruber and Blake (1996) also found persistence in performance over one to three year periods and that information about future performance is affected by past performance. Carhart (1997) observed short-term persistence in equity mutual fund returns but the one-year momentum in share returns anomaly could largely explain this. Phelps and Detzel (1997) found no meaningful positive persistence in performance.

From the preceding studies it can be concluded that there is evidence of persistence of performance but it is mainly short term and, if the sample excluded funds that ceased trading during the period, survivorship bias may cause returns to be overstated. The contrary results of the persistence of performance studies may be explained if persistence is a function of the specific period studied and its length. This is pursed further in the following section. The benchmark used in any analysis is of importance, as results can either be overstated or understated if the benchmark is inappropriate.

\section{South African studies}

Studies of persistence in performance of South Africa unit trusts include those of Meyer (1998), Von Wielligh and Smit (2000), Firer, Beale, Edwards, Hendrie and Scheppening (2001) and Collinet and Firer (2003). Meyer (1998) tested the 'repeat winner' phenomenon for South African unit trusts and found some persistence in performance, over two-year periods. The repeat winner 
phenomenon was found to exist, for both nominal and risk adjusted returns, using two-year periods but was much weaker over the one-year intervals. The study contained a potential bias because non-diversified portfolios were included while the ALSI was used as a benchmark.

Von Wielligh and Smit (2000) produced evidence of positive persistence in performance of South African unit trusts. In the short-run there was some persistence in performance for the General Equity unit trusts but none for the All Unit Trust portfolio. Long-run persistence in performance existed for the General Equity unit trust portfolio and to a certain extent for the All Unit Trust portfolio. Furthermore, the bottom-performing portfolio remained the worst performer while the best and average portfolios remained the best and average performers. In conclusion, there was some long-run evidence of persistence in performance among South African unit trusts. These results concurred with Meyer's results, which suggested that persistence in performance existed over a longer period for South African unit trusts.

Firer et al. (2001) showed short-run persistence in performance, finding that an investment strategy of selecting past superior performers may improve investment returns, particularly in the general equity unit trust sector. These results indicate short-run persistence in performance in contrast to other South African studies. The authors attribute this to the use a larger data set and different method of testing for persistence in performance.

Collinet and Firer (2003) analysed the relative performance of general equity unit trusts over a twenty-year period, using a database free of survivorship bias. The results proved to be highly sensitive to the holding period length, the time period studied and the ending date of the analysis. A positive but weak relationship existed between past and future rankings. However, as the holding period lengthens the relationship weakens. The strongest relationship, for both winning and losing funds, was evident for holding and formation periods of six months. The authors argue that the most important cause of the disparate results obtained in earlier South African studies was the selection of different sample periods. These short-term studies using different sample periods and non-equivalent holding periods could not be expected to yield consistent results. An important result, relevant to the following empirical analysis, was that individual unit trusts did not perform consistently for any length of time.

The South African studies of persistence of unit trust performance are contradictory and inconclusive. There is justification for further work in this area using more recent data and a different time frame. The short-term sample period of this study may, however, be a problem if one accepts the findings of Collinet and Firer (2003) that shortterm studies will inherently yield inconsistent results.

\section{Data and methodology}

Twenty selected unit trusts operating in South Africa from January 1998 to December 2002 were included in the sample. Funds were selected from the Domestic AA
Prudential, Domestic Equity General, Domestic Equity Growth, Domestic Equity Smaller Companies and Domestic Equity Value sectors. All unit trusts had chosen the JSE All Share Index as a benchmark to judge performance. This was regarded as a representative sample of this class of funds at the beginning of the sample period. However, post 1998 there was very rapid growth in the number of registered unit trusts and the twenty selected funds do not necessarily represent the unit trust industry at the end of the period.

Two models are used to test financial performance. To test performance against the ASI benchmark the CAPM is applied to each fund on an annual basis. This involves 100 regression equations and the testing for statistical significance of the Jensen Alpha for each equation. Alternatively, instead of using the ASI as the benchmark sector indices for Industrial, Mining Resources and Financial are used as benchmarks. The additional variables require the application of the APT model. Again, 100 equations are estimated and the statistical robustness of these results is compared to those of the CAPM.

Weekly closing prices of the unit trusts, used to calculate the rates of return, were obtained from the JSE database. Transaction costs that relate to buying and selling of unit trusts and management fees have not been included, nor have dividend yields associated with the unit trusts and JSE indices. This means that the rates of return depend solely on price appreciation or depreciation and this information is used to assess persistence of performance.

Rates of return using weekly data were obtained by using the following formula:

$\mathrm{R}_{\mathrm{it}}=\frac{\mathrm{P}_{\mathrm{it}}-\mathrm{P}_{\mathrm{it}-1}}{\mathrm{P}_{\mathrm{it}-1}}$

where:

$\mathrm{R}_{\mathrm{it}}$ is the weekly rate of return of unit trust $\mathrm{i}$ in period $\mathrm{t}$;

$\mathrm{P}_{\text {it }}$ is the weekly closing price (repurchase price) of unit trust $\mathrm{i}$ in period $\mathrm{t}$; and

$\mathrm{P}_{\mathrm{it}-\mathrm{1}}$ is the weekly closing price of unit trust $\mathrm{i}$ in period $\mathrm{t}-1$

The same formula was used to determine the weekly rate of return on the JSE indices.

The 90-day Banker's Acceptance rate was used as the riskfree rate of return with annualised rates being adjusted to give a weekly return.

The unit trust's benchmarks were obtained from the 2002 and 2003 Profile's Unit Trusts Handbook. All the unit trusts selected used the JSE All Share Index as a fund benchmark. Investors expect unit trust managers to beat the benchmark set for the fund and therefore it is important that an appropriate target be set. According to previous studies, namely Grinblatt and Titman (1992), Hendricks et al. (1993) and Malkiel (1995), an incorrect benchmark can influence the assessment of superior performance of the unit trust. Thus, the selected unit trusts are not only tested using the 
ASI as a benchmark in the CAPM, but also by means of the APT model which permits more than one benchmark.

For the APT testing a three-factor APT model was adopted. Notwithstanding that the JSE ASI benchmark criterion was the choice of the twenty unit trusts tested, it was found that the majority of the funds were weighted quite heavily in the Industrial, Mining Resource and Financial sectors. It was thus felt that a benchmark created by using these indices would be a more relevant benchmark than the ASI.

CAPM explains the relationship between systematic risk and expected return in the market (Ross, Westerfield, Jordan \& Firer, 2001: 366). The CAPM can be represented by the following equation:

$E\left(R_{i}\right)=R_{f}+\beta_{i}\left[E\left(R_{m}\right)-R_{f}\right]$

where:

$E\left(R_{i}\right)$ is the expected rate of return on asset $i ; R_{f}$ is the riskfree rate of return; $\left[E\left(R_{m}\right)-R_{f}\right]$ is the expected market risk premium and $\beta_{i}$ is the measure of the amount of systematic risk associated with the particular asset $\mathrm{i}$.

For the econometric estimates the above formula was modified slightly:

$\left(R_{i}-R_{f}\right)=\alpha+\beta_{i}\left(R_{m}-R_{f}\right)+e$

where:

$\left(R_{i}-R_{f}\right)$ is the differential expected return on the unit trust over and above the risk-free rate of return;

$\left(\mathrm{R}_{\mathrm{m}}-\mathrm{R}_{\mathrm{f}}\right)$ is the differential return on the market (JSE ASI) over and above the risk-free rate of return;

$\beta_{\mathrm{i}}$ is the beta of the unit trust; $\alpha$ is the Jensen's measure of the unit trust's performance and e is the error term.

The unit trust data is also analysed using the multi-factor APT model:

$\left(R_{i}-R_{f}\right)=\alpha+\beta_{i}\left(R_{\text {ind }}-R_{f}\right)+\beta_{i}\left(R_{\min }-R_{f}\right)+$

$\beta_{\mathrm{i}}\left(\mathrm{R}_{\text {fin }}-\mathrm{R}_{\mathrm{f}}\right)+\mathrm{e}$

where:

$\left(\mathrm{R}_{\text {ind }}-\mathrm{R}_{\mathrm{f}}\right)$ is the expected differential return on the Industrial Index over and above the risk-free rate;

$\left(\mathrm{R}_{\min }-\mathrm{R}_{\mathrm{f}}\right)$ is the expected differential return on the Mining Index over and above the risk-free rate;

$\left(\mathrm{R}_{\mathrm{fin}}-\mathrm{R}_{\mathrm{f}}\right)$ is the expected differential return on the Financial Index over and above the risk-free rate; and,

$\beta_{\mathrm{i}}$ 's measure the exposure of the unit trust to each of the indices.

The Jensen performance measure is central to the investigation in this paper. This is the alpha $(\alpha)$ in the CAPM and APT equations. It is a measure of the return on an investment over and above the return predicted by the CAPM or APT betas. Any superior performance by asset managers will result in a positive alpha value indicating that the managers have been able, during the period under consideration, to select undervalued securities and exhibit superior market timing and stock selection skills. Alternatively, an asset manager whose funds exhibit inferior performance in relation to the CAPM or APT will achieve significant negative alphas (Reilly \& Brown, 2003: 1116). It is realised that the asset managers of a particular fund may have changed during the selected period. The tests are therefore of the funds' performance rather than a particular asset team.

The following hypotheses are tested for both the CAPM and APT models:

$\mathrm{H}_{\mathrm{o}}: \alpha=0$

$\mathrm{H}_{1}: \alpha>$ or $<0$

If the null hypothesis is accepted, it states that Jensen's alpha does not differ significantly from zero and the unit trust does not exhibit superior performance. Whereas if the alternative hypothesis is accepted, then Jensen's alpha is greater than zero and the unit trust exhibits superior performance. A statistically significant negative alpha would represent inferior performance.

OLS regression estimates were obtained using equations (2) and (3) to determine the slope $(\beta)$ and intercept $(\alpha)$ coefficients of the equations. These were tested at the five percent level of significance.

Following the methodology put forth by Goetzmann and Ibbotson (1994) the alpha estimates from the CAPM and APT regressions may be used to test whether there was persistence or non-persistence in the performance of the unit trusts. To obtain a measure of the extent, to which persistence in performance exists, the alpha values from all twenty unit trusts, each year, were regressed on the alpha values from the previous year to obtain a new alpha and beta estimate, using the following equation:

$\alpha_{t}=\gamma+\beta\left(\alpha_{t-1}\right)$

where:

$\alpha_{t}$ is the alpha value from the OLS regression in time $t ; \alpha_{t-1}$ is the alpha value from the OLS regression in time $t-1 ; \gamma$ is the new intercept term; and, $\beta$ is the new slope coefficient.

The hypotheses tested were:

$\mathrm{H}_{\mathrm{o}}: \beta=0$

$\mathrm{H}_{1}: \beta \neq 0$

The hypothesis is set up to determine whether or not there is a statistical relationship between the current year's alpha values and the previous year's alpha values. If such a relationship exists the performance of the previous period is reflected in the current period, indicating persistence in 
performance. If the null hypothesis is accepted there is no relationship between performance in one year and performance in the previous year. Alternatively, if the null hypothesis is rejected and the alternative hypothesis is accepted, there is a relationship between the performances in one year to the performance in the previous year.

Multicollinearity may occur in the APT tests if there is a linear relationship between the explanatory variables (Gujarati, 1999:313). The problem causes difficulty in identifying the unique influences that each explanatory variable has on the dependent variable. In this study multicollinearity may be present if there is a linear relationship between the Industrial, Mining and Financial indices used to explain the behaviour of unit trusts returns. However, as will be discussed in a following section this was found not to be the case.

\section{Results}

\section{CAPM results}

The Jensen alpha tests are summarised in Table 1. Twenty alphas were estimated for each year (one for each unit trust).The alphas are divided into four categories either positive and statistically significant (henceforth P-SS), negative and statistically significant (N-SS), positive and statistically insignificant (P-SI) or negative and statistically insignificant (N-SI). Statistical significance is measured at the 5 percent level. The numbers in parentheses indicate the number of unit trusts that fell into each category in each period. The percentages refer to the proportion of the twenty unit trusts which fell into each category in each year.

Table 1: CAPM results according to alpha values

\begin{tabular}{l|c|c|c|c}
\hline & $\begin{array}{c}\text { Positive \& } \\
\text { Statistically } \\
\text { Significant }\end{array}$ & $\begin{array}{c}\text { Positive \& } \\
\text { Statistically } \\
\text { Insignificant }\end{array}$ & $\begin{array}{c}\text { Negative \& } \\
\text { Statistically } \\
\text { Significant }\end{array}$ & $\begin{array}{c}\text { Negative \& } \\
\text { Statistically } \\
\text { Insignificant }\end{array}$ \\
\hline $\mathbf{1 9 9 8}$ & $0 \%(0)$ & $55 \%(11)$ & $0 \%(0)$ & $45 \%(9)$ \\
\hline $\mathbf{1 9 9 9}$ & $5 \%(1)$ & $55 \%(11)$ & $0 \%(0)$ & $40 \%(8)$ \\
\hline $\mathbf{2 0 0 0}$ & $0 \%(0)$ & $15 \%(3)$ & $15 \%(3)$ & $70 \%(14)$ \\
\hline $\mathbf{2 0 0 1}$ & $15 \%(3)$ & $30 \%(6)$ & $10 \%(2)$ & $45 \%(9)$ \\
\hline $\mathbf{2 0 0 2}$ & $10 \%(2)$ & $65 \%(13)$ & $0 \%(0)$ & $25 \%(5)$ \\
\hline
\end{tabular}

In 1998 no unit trusts fell into the P-SS or N-SS categories, whereas 55 percent and 45 percent of the unit trusts were categorised into the P-SI and N-SI categories respectively. Therefore, the CAPM did not identify any statistically significant superior performance in this period although 55 percent of the funds could possible have exhibited a superior performance. However, these funds did not meet the statistical test for superior performance.

In the 1999 period, one unit trust was classified in the P-SS category, namely the Allan Gray Equity fund. The P-SI and $\mathrm{N}-\mathrm{SS}$ categories remained the same as in the 1998 period with 55 percent of the unit trusts falling into the P-SI category and no funds falling into the N-SS category. While 40 percent of the unit trusts were classified in the N-SI category as opposed to 45 percent in the 1998 period. The positive alpha values show the possibility of superior performance but are not supported by tests for significance at the 5 percent level of significance.

In the 2000 period, no funds were classified as P-SS. There was a reduction in the proportion of funds ( 55 percent to 15 percent) classified as P-SI while there was an increase in the number of funds classified as N-SS and N-SI ( 0 percent to 15 percent and 40 percent to 70 percent respectively). The funds classified as N-SS were Nedbank Growth fund, Investec Growth fund and Investec Emerging Companies fund. Thus there is fairly strong evidence that these funds exhibited an inferior performance in what was a difficult year for equity investors.

The following 2001 period, resulted in an increase in the number of funds (zero percent to 15 percent) classified as P$\mathrm{SS}$, these funds included the BOE Value fund, the Investec Value fund and the Futuregrowth Albaraka Equity fund. Furthermore, there was an increase in the number of funds (15 percent to 30 percent) that were classified in the P-SI category. There was also a decrease in the number of funds classified in the N-SI category (70 percent to 45 percent) and a decrease in the number of funds classified in the N-SS category (15 percent to 10 percent). The N-SS funds included the Sanlam Prime Growth Trust fund and the Sanlam General fund.

Finally, in the 2002 period, there were only two funds classified in the P-SS category namely, the Allan Gray Equity fund and the Investec Value fund. There was, however, an increase in the number of funds classified in the P-SI category (30 percent to 65 percent) as well as a decrease in the number of funds classified in the N-SS category ( 10 percent to 0 percent). Furthermore, there was a decrease in the number of funds classified in the N-SI category ( 45 percent to 25 percent).

In summary, of the 100 estimated equations (twenty funds for five years), 44 observations had positive but statistically insignificant alpha values and 45 observations had negative but statistically insignificant alpha values. This shows no statistical support for the proposition that unit trust managers can provide above average returns. Over the five years analysed only six observations were P-SS. Allan Gray and Investec Value appeared twice and four other funds once. Five funds showed significantly below average performance.

\section{APT results}

Because high $\mathrm{R}^{2}$ values and low t-statistic values were present in some of the APT results, multicollinearity was suspected. Using conventional tests for multicollinearity, it was found that multicollinearity did not exist between the explanatory variables, namely between the Industrial, Mining Resource and Financial Indices. 
Table 2: APT results according to alpha values

\begin{tabular}{l|c|c|c|c}
\hline & $\begin{array}{c}\text { Positive \& } \\
\text { Statistically } \\
\text { Significant }\end{array}$ & $\begin{array}{c}\text { Positive \& } \\
\text { Statistically } \\
\text { Insignificant }\end{array}$ & $\begin{array}{c}\text { Negative \& } \\
\text { Statistically } \\
\text { Significant }\end{array}$ & $\begin{array}{c}\text { Negative \& } \\
\text { Statistically } \\
\text { Insignificant }\end{array}$ \\
\hline $\mathbf{1 9 9 8}$ & $0 \%(0)$ & $15 \%(3)$ & $0 \%(0)$ & $85 \%(17)$ \\
\hline $\mathbf{1 9 9 9}$ & $5 \%(1)$ & $85 \%(17)$ & $0 \%(0)$ & $10 \%(2)$ \\
\hline $\mathbf{2 0 0 0}$ & $0 \%(0)$ & $5 \%(1)$ & $20 \%(4)$ & $75 \%(15)$ \\
\hline $\mathbf{2 0 0 1}$ & $20 \%(4)$ & $65 \%(13)$ & $0 \%(0)$ & $15 \%(3)$ \\
\hline $\mathbf{2 0 0 2}$ & $15 \%(3)$ & $55 \%(11)$ & $0 \%(0)$ & $30 \%(6)$ \\
\hline
\end{tabular}

Table 2 is essentially the same as Table 1 except for the fact that it summarises the results obtained from the APT testing. The inclusion of three explanatory variables should enable a better analysis of funds with portfolios that have sector allocations significantly different from the proportions in the ASI.

During 1998 no unit trusts were classified as P-SS or N-SS. However, 15 percent of the unit trusts were classified as P$\mathrm{SI}$ and 85 percent were classified as N-SI. Thus there is no statistical support for the proposition that unit trust managers are able to deliver above average equity returns. On the other hand, there were no statistically significant underperformers. All of the funds fall into a grey area but most indicate poor rather than above average performance

In the 1999 period, there was one unit trust, namely the Allan Gray Equity fund, which was classified as P-SS. Again, no unit trust was classified in the N-SS category. However, there was a turnaround in the number of funds classified as P-SI (15 percent to 85 percent) whereas there was a decrease in the number of funds classified as N-SS ( 85 percent to 10 percent).

In the 2000 period, no funds were classified as P-SS, while there was a decrease in the number of funds classified as PSI ( 85 percent to 5 percent). There was however an increase in the number of funds classified as N-SI and N-SS $(0$ percent to 20 percent and 10 percent to 75 percent respectively). The statistically significant underperformers were ABSA General, Nedbank Growth, Investec Growth and Investec Emerging Companies.

During 2001, as was the case with the CAPM results, there was a large increase in the number of funds classified as PSS (0 percent to 20 percent). These funds included the Allan Gray Equity fund, the BOE Value fund, the Investec Value fund and the Futuregrowth Albaraka fund. There was a decrease in the number of funds classified as N-SI (20 percent to 0 percent) and N-SS (75 percent to 15 percent), while there was an increase in the number of funds classified as being P-SI ( 5 percent to 65 percent).

Finally, in the 2002 period, there was a slight fall in the number of funds classified as P-SS (20 percent to 15 percent). The Futuregrowth fund fell out of the rankings. Furthermore, there was a decrease in the number of funds classified as P-SI (65 percent to 55 percent) while the number of funds classified as N-SI remained the same as in 2001 (0 percent). There was, however, an increase in the number of funds classified as N-SI (15 percent to 30 percent).
In summary, of the 100 estimated equations, using the APT model, 45 had positive but statistically insignificant alpha values and 43 had negative and statistically insignificant alpha values. Again this showed little support for fund managers being able to achieve superior returns. However, eight estimates had positive and statistically significant alpha values and 4 observations had negative and statistically significant alpha values.

In general, the APT model did not outperform the CAPM model showing a very similar breakdown of funds into the four categories. In the 2000 period the APT identified one more fund in the N-SS category than the CAPM. In the 2001 period, the APT model identified one more fund in the P-SS category. In the N-SS category the APT model did not identify any funds while the CAPM revealed two funds. During the 2002 period the APT identified one more fund in the P-SS category. These are minor differences and do not alter the overall picture of twenty unit trusts over a period of five years being, at best, able to beat the market eight times.

\section{Benchmark appropriateness}

If a unit trust, or mutual fund, investment portfolio contained exactly the same proportions of assets as those making up the ASI, a CAPM estimate would show an $\mathrm{R}^{2}$ of $100 \%$, a beta of unity and an alpha of zero. A fund manager who tracks the market will not, of course, be able to achieve superior performance according to Jensen's alpha test. The achievement of a significantly positive alpha requires a portfolio biased towards those sectors which experience above average returns. As a consequence the CAPM estimates should yield a relatively low $\mathrm{R}^{2}$ and beta. The selection of the JSE ASI as a benchmark, by the unit trusts in the sample, reflects an intention to beat the market. The more defensive a fund manager and the more the manager mimics the ASI the less likely the fund's performance will meet the alpha test.

Instead of benchmarking the ASI a unit trust managing a portfolio that specialised in sector investment could benchmark sector indices. An APT estimate would show that a fund specialising in industrial, mining and financial shares and arranging its portfolio to track the Industrial, Mining and Financial indices has a zero alpha, statistically significant betas for all three sectors and a $\mathrm{R}^{2}$ close to unity. If a unit trust focuses its investment strategy on a few sectors the APT model is appropriate and sector indices should be used as benchmarks. The APT model is appropriate for sector specialisation but a fund manager will only achieve a positive significant alpha by arranging a portfolio in such a way that its composition differs from that of the indices. A positive significant alpha should be accompanied by a lower $\mathrm{R}^{2}$ and beta coefficients.

These propositions are examined in Table 3 which presents the $\mathrm{R}^{2} \mathrm{~s}$ and betas of the four most successful funds identified in the previous section. The funds that fall into the P-SS category are the Allan Gray Equity fund, the Futuregrowth Albaraka Equity fund, the BOE Value fund and the Investec Value fund. For comparative purposes a tracker fund, Investec Index, with an alpha that did not differ significantly from zero, is included. 
Table 4: $R^{2}$ and $\beta$ comparisons

\begin{tabular}{|c|c|c|c|c|}
\hline & CAPM R ${ }^{2}$ & APT $\mathbf{R}^{2}$ & CAPM $\beta$ & $\begin{array}{c}\text { APT } \beta \\
\text { I=Ind, } M=\text { Mining, } F=\text { Finance }\end{array}$ \\
\hline \multicolumn{5}{|c|}{ Allan Gray Equity Fund } \\
\hline 1999 & 0,385 & 0,357 & 0,535 & $0,219(\mathrm{M})$ and $0,182(\mathrm{~F})$ \\
\hline 2001 & 0,738 & 0,772 & 0,457 & $0,231(\mathrm{I})$ and $0,186(\mathrm{~F})$ \\
\hline 2002 & 0,476 & 0,475 & 0,412 & $0,142(\mathrm{I})$ and $0,156(\mathrm{M})$ \\
\hline \multicolumn{5}{|c|}{ Futuregrowth Albaraka fund } \\
\hline 2001 & 0,654 & 0,714 & 0,465 & $0,394(\mathrm{I})$ \\
\hline \multicolumn{5}{|l|}{ BOE Value } \\
\hline 2001 & 0,477 & 0,559 & 0,385 & $0,279(\mathrm{~F})$ \\
\hline 2002 & 0,445 & 0,514 & 0,437 & $0,160(\mathrm{M})$ and $0,239(\mathrm{~F})$ \\
\hline \multicolumn{5}{|c|}{ Investec Value } \\
\hline 2001 & 0,508 & 0,635 & 0,391 & $0,267(\mathrm{I})$ and $0,227(\mathrm{~F})$ \\
\hline 2002 & 0,168 & 0,209 & 0,219 & $0,176(\mathrm{I})$ \\
\hline \multicolumn{5}{|l|}{ Investec Index } \\
\hline 2001 & 0,962 & 0,958 & 0,947 & $0,28(\mathrm{I}), 0,33(\mathrm{M})$ and $0,25(\mathrm{~F})$ \\
\hline 2002 & 0,956 & 0,948 & 0,894 & $0,24(\mathrm{I}), 0,43(\mathrm{M})$ and $0,11(\mathrm{~F})$ \\
\hline
\end{tabular}

Note: The betas are all significant at the 5 percent level.

Using the CAPM, the tracker fund, as expected, has a $\mathrm{R}^{2}$ close to unity. The beta coefficient is highly significant and also close to unity. This shows a very close behavioural relationship between index fund returns and those of the ASI. A similar conclusion is reached in terms of the APT model. All of the funds identified as superior performers, in the relevant years, have much lower $\mathrm{R}^{2} \mathrm{~s}$ and betas. The CAPM beta values range from 0.22 to 0.53 and are all statistically different from unity. However, if the funds had large cash holdings, as may be the case in bear markets, the beta would be expected to be below one but not to the extent shown above. The values of the APT beta coefficients that were statistically significant are relatively lower than those for the tracker estimates. These results confirm the proposition that superior performance is associated with relatively low $\mathrm{R}^{2} \mathrm{~s}$ and betas.

The low beta and $\mathrm{R}^{2}$ values show that risk adjusted unit trust returns behaved differently from the market benchmark because of relatively low systematic risk. The above average performance attributed to these funds was achieved by taking on more unsystematic risk. A fund manager intending to beat the market must invest in assets that do not follow the market trend. This increases the risk of over or under performance

A comparison of the $R^{2}$ s over the full sample of 100 estimates shows the APT model to have, on average, higher values than the CAPM. In terms of goodness of fit the APT model may, at times, be more appropriate for measuring superior performance. For funds that give additional weight to certain sectors, in order to pursue exceptional returns, a benchmark consisting of at least the Industrial, Financial and the Mining indices may be preferable to the ASI.
Measuring the magnitude of persistence in performance

To clarify if there was any persistence in performance in general for all the funds, the alpha values obtained from the CAPM and APT models for each year were regressed on the previous year's alpha values and the results are presented in Tables 4 and 5 below. A positive and statistically significant beta coefficient would show that previous performance is related to current performance.

From Table 4, the beta coefficients are statistically insignificant except for 1999-2000. For this period the null hypothesis of performance being unrelated to past performance is rejected. There appears to be some carry over of 1999 performance into 2000. Persistence is evident over these two years but does not progress to the following period. The $\mathrm{R}^{2}$ value indicates that performance in 1999 contributed 21 percent to the performance in 2000. The empirical support is weak for persistence of performance in terms of the CAPM.

From Table 5, persistence performance is evident in 1999 2000 period as well as 2001-2002. Again, for these periods, the null hypothesis of performance being unrelated to past performance can be rejected. Comparing the $\mathrm{R}^{2}$ values for the two periods, 2001-2002 has a much higher $\mathrm{R}^{2}$ value (74 percent) than 1999-2000 (27 percent). The APT model lends stronger support to the persistence of performance hypothesis than the CAPM. by identifying a strong carry over into the 2001-2002 period. 
Table 4: Persistence in performance predicted by the CAPM alpha values

\begin{tabular}{l|c|c|c|c|c}
\hline CAPM & Gamma & $\begin{array}{c}\text { Gamma } \\
\text { t-stat }\end{array}$ & Beta & $\begin{array}{c}\text { Beta } \\
\text { t-stat }\end{array}$ & R-squared \\
\hline $1998-1999$ & 0,00055 & 0,7379 & 0,27611 & 1,063 & 0,059 \\
\hline $1999-2000$ & 0,00167 & $2,296^{*}$ & 0,47809 & $2,196^{*}$ & 0,211 \\
\hline $2000-2001$ & $-0,00212$ & $-3,355^{*}$ & $-0,013459$ & $-0,797$ & 0,034 \\
\hline $2001-2002$ & $-0,01172$ & $-1,217$ & 4,2194 & 0,766 & 0,031 \\
\hline
\end{tabular}

* Statistically significant at the 5 percent level

Table 5: Persistence in Performance Predicted by the APT Model's Alpha Values

\begin{tabular}{c|c|c|c|c|c}
\hline APT & Gamma & $\begin{array}{c}\text { Gamma } \\
\text { t-stat }\end{array}$ & Beta & $\begin{array}{c}\text { Beta } \\
\text { t-stat }\end{array}$ & R-squared \\
\hline $1998-1999$ & $-0,00304$ & $-3,988^{*}$ & 0,17988 & 0,6635 & 0,0244 \\
\hline $1999-2000$ & 0,00297 & $4,146^{*}$ & 0,51689 & $2,582^{*}$ & 0,270 \\
\hline $2000-2001$ & $-0,00241$ & $-3,244^{*}$ & $-0,12358$ & $-0,6073$ & 0,020 \\
\hline $2001-2002$ & 0,00083 & $2,117^{*}$ & 1,5387 & $7,238^{*}$ & 0,744 \\
\hline
\end{tabular}

* Statistically significant at the 5 percent level

In the 1999-2000 period the persistence detected by the CAPM was mainly negative persistence as 30 percent of the funds exhibited negative and statistically insignificant performance in both periods, whereas, only 10 percent of the funds exhibited positive performance in both periods. In the 2000-2002 period, the APT model detected mainly positive persistence as 55 percent of the funds had positive alphas in both periods, although a large proportion of these were statistically insignificant.

In general, there are more negative (significant and insignificant) than positive (significant and insignificant) alphas in the unit trust sample. Conditions were bearish and the market swung from overall negative returns in 1998 to positive in 1999, back to negative in 2000, positive in 2001 and a mixed bag in 2002. Thus, it was difficult for any single unit trust to buck the trend by yielding persistent positive or negative returns. The unit trusts in the sample tended to under perform the market but followed the cyclical pattern of the ASI and the sector indices. The few funds that achieved superior performance, with some degree of persistence, in these bear markets may be considered exceptional investment vehicles.

\section{Conclusion}

The paper evaluates unit trust performance in terms of two models, which relate unit trust returns to portfolio risk and the overall, or sector, share market premium. Superior performance, defined as a return over and above that determined by the market premium, was tested for twenty unit trusts over a five year period. Remarkably few of the twenty unit trusts examined were able to achieve a superior performance, in any one year, in terms of the Jensen test. Four unit trusts managed to beat the market, measured by both the CAPM and APT models, and the balance did not. Six funds achieved negative, inferior performance in terms of one or other model. Growth funds fared poorly compared to value funds but this has been the worldwide experience in bear markets. The short term nature of the study may have precluded periods where other styles of investment were more successful.
Although some of the value funds outperformed the market index it is questionable whether those funds should compare their performance to the JSE ASI. The objectives and composition of these funds dictates that they do not follow market trends. Value funds build their portfolios by selecting currently undervalued shares and do not focus on a general equity approach. The funds may find value shares in particular sectors. When underperforming shares recover value funds show superior performance. There may, however, be periods where value funds under perform the market but this does not mean that they are failing to meet investor expectations. In the case of value funds it may be argued that an absolute benchmark rather than a relative benchmark, such as the JSE ASI Index, would be more appropriate.

The remaining funds exhibited performances that showed no special management ability - good or bad - earning a return related to market risk. This finding is not out of line with other studies, international and South African.

In drawing a comparison between the CAPM (JSE ASI benchmark) and the APT model (Financial, Industrial and Mining Resource indices benchmarks), the APT appeared, in terms of the $\mathrm{R}^{2}$ values of the two models, to be a better statistical model when identifying funds that had positive and statistically significant alpha values. These funds focussed on certain sectors to enhance performance rather than taking a general equity approach. The funds that exhibited positive superior performance were not taking a general equity approach, which implies wide diversification, but focussing on certain sectors. This brings into question the use of the ASI as appropriate benchmark to judge performance. If, however, the fund specified a particular sector index as a benchmark this might severely reduce the flexibility of the fund managers to shift between sectors in changing economic circumstances.

To test for persistence in performance the twenty funds were treated as a portfolio and any significant over and underperformance, carried over from one year to the next, observed. The magnitude of persistence in performance 
measured by both the CAPM and APT models showed weak evidence of short-run persistence in performance. Only one out of four periods using the CAPM results and two out of four periods, using the APT results indicated any persistence in performance. This persistence was short-lived as found in recent South African studies and many of the larger international market studies. Although treating the twenty funds as a portfolio and then testing year on year performance gives an overall picture of managerial performance the important issue is individual fund management.

The sample used in the study was relatively small because of the limited number of funds which had met the selection criteria - being in existence since 1998 and using the JSE All Share Index as a benchmark. The results of the analysis cannot, therefore, be generalised to the South African unit trust market as a whole. Survivorship bias is not a problem because very few South African unit trusts disappeared during the five year period examined. However, many new funds were established during this time and are not included in the sample. These persistence results cannot be generalised to the whole unit trust industry and are limited to those that existed in 1998 and used the ASI as a benchmark.

The sample period was also relatively short and covered a period where the share market was very volatile, swinging from negative average returns to positive and then back to negative. If persistence of performance depends on the time period studied and its length the results found here may be unique to this particular time period.

There could be a possible problem associated with the absence of transaction costs and the omission of dividend yields. However, both costs and yields and are relatively low and stable and their exclusion may not prove to be too serious an omission. The true test of management performance is determined by the ability to achieve exceptional capital gains and to minimise capital losses

Finally, further research is needed to determine the quality of management performance where an absolute benchmark is adopted. Not all unit trust investors are happy to follow the ebb and flow of the market but would prefer a return that on average beats the risk free rate, the return on bonds, inflation or some similar target for a given holding period. This might prove to be a much stronger test of management performance than the ASI benchmark. There is not really much satisfaction for an investor in knowing that, in a bear market, the fund manager 'beat the market' when in fact real returns were negative.

\section{References}

Bodie, Z., Kane, A. \& Marcus, A.J. 2001. Essentials of investments. $4^{\text {th }}$ edition. New York: McGraw-Hill Company.

Brealey, R. \& Myers, S. 1984. Principles of corporate finance. $2^{\text {nd }}$ edition. McGraw-Hill Company.

Carhart, M.M. 1997. 'On persistence in mutual fund performance’, The Journal of Finance, 52(1):57-82.
Cole, R. 1997. Getting started in unit and investment trusts. Chichester: John Wiley \& Sons.

Collinet, L. \& Firer, C. 2003. 'Characterising persistence of performance amongst South African general equity unit trusts, Omega', The International Journal of Management Science, 31:523-538.

Elton, E.J., Gruber, M.J. \& Blake, C.R. 1996. 'The persistence of risk-adjusted mutual fund performance', The Journal of Business, 69(2):133-157.

Falkena, H.B., Fourie, L.J. \& Kok, W.J. 1995. The South African financial system. Cape Town: Southern Book Publishers.

Firer, C., Beale, J.P., Edwards, M.D., Hendrie, J.N. \& Scheppening, D.C. 2001. 'The persistence of performance of South African unit trusts', The South African Journal of Business Management, 32(2):1-8.

Goetzmann, W.N. \& Ibbotson, R.G. 1994. 'Do winners repeat?', The Journal of Portfolio Management, 20(2):9-18.

Grinblatt, M. \& Titman, S. 1989. 'Mutual fund performance: An analysis of quarterly portfolio holdings', The Journal of Business. 62(3):393-416.

Grinblatt, M. \& Titman, S. 1992. 'The persistence of mutual fund performance', The Journal of Finance, 47(5):19771984.

Grinblatt, M. \& Titman, S. 2002. Financial markets and corporate strategy. $2^{\text {nd }}$ edition. New York: McGraw-Hill Company.

Gujarati, D. 1999. Essentials of econometrics. $2^{\text {nd }}$ edition. Singapore: McGraw-Hill Company.

Hendricks, D., Patel, J. \& Zeckhauser, R. 1993. 'Hot hands in mutual funds: Short-run persistence of relative performance, 1974 - 1988', The Journal of Finance, 48(1):93-130.

Hill, C.R., Griffiths, W.E. \& Judge, G.G. 2001. Undergraduate econometrics. $2^{\text {nd }}$ edition. New York: John Wiley \& Sons, Inc.

Jensen, M.C. 1968. 'The performance of mutual funds in the period 1945 - 1964', The Journal of Finance, 23(2):389416.

Knight, E.T. \& Firer, C. 1989. 'The performance of South African unit trusts', The South African Journal of Economics, 57(1):52-68.

Lee, C.F. \& Finnerty, J.E. 1990. Corporate finance theory, method and applications. New York: Harcourt Brace Jovanovich.

Lumby, S. 1994. Investment appraisal and financial decisions. $5^{\text {th }}$ edition. London: Chapman \& Hall. 
Malkiel, B.G. 1995. 'Returns from investing in equity mutual funds 1971 to 1991', The Journal of Finance, 50(2):549-572.

Meyer, M.C. 1998. 'The persistence of unit trust performance for the period July 1985 - June 1995', The South African Journal of Business Management, 29(3):100108.

Oldert, N. 2001. Understanding unit trusts. Johannesburg: Profile Media.

Peterson, H.C. \& Lewis, W.C. 1999. Managerial economics. $4^{\text {th }}$ edition. New Jersey: Prentice-Hall, Inc.

Phelps, S. \& Detzel, L. 1997. 'The non-persistence of mutual fund performance', The Quarterly Journal of Business and Economics, 36(2):55-69.

Profile's. 2002. Unit Trust Handbook 2002. Johannesburg: Profile Media.

Profile's. 2003. Unit Trust Handbook 2003. Johannesburg: Profile Media.

Reilly, F.K. \& Brown, K.C. 2003. Investment analysis and portfolio management. $7^{\text {th }}$ edition. Mason, Ohio: Thompson South Western.

Ross, S., Westerfield, R.W., Jordan, B.D. \& Firer, C. 2001. The fundamentals of corporate finance. $2^{\text {nd }}$ South African edition. Roseville, NSW, Australia: McGraw-Hill Company.

Von Wielligh, J.F.C. \& Smit, E.vd M. 2000. 'Persistence in the performance of South African unit trusts', The South African Journal of Business Management, 31(3):120-129. 